\title{
AS REFORMAS DO CÓDIGO DE PROCESSO CIVIL COMO NOVAS \\ PERSPERCTIVAS DE ABERTURAS AO ACESSO À JUSTIÇA
}

\section{THE PROCESS OF REFORMS CIVIL CODE AS NEW OPENINGS PROSPECTS TO ACCESS TO JUSTICE}

\author{
${ }^{1}$ Luiz De França Belchior Silva
}

\section{Resumo}

Este trabalho visa analisar o acesso à justiça sob a ótica das últimas reformas do judiciário brasileiro que tentam contemporizar a morosidade da justiça na prestação da tutela jurisdicional, bem como as reformas surgidas através do novo Código de Processo Civil, em que a razoável duração do processo consolidou-se como princípio fundamental infraconstitucional e, ainda, outros mecanismos processuais, como o processo eletrônico, o calendário processual, a Conciliação, além de alternativas na resolução de controvérsias, como Mediação e Arbitragem, fazendo com que a Justiça seja vista como sistema mais amplo, o Tribunal Multiportas, apresentando-se de grande relevância no cenário jurídico processual.

Palavras chave: Acesso à Justiça; Razoável duração do processo; Pacificação Social;

Conciliação. Mediação

\begin{abstract}
This work aims to analyze the access to justice from the perspective of the last Brazilian judicial reforms that attempt to compromise the slow pace of justice in the provision of judicial protection, as emerged reforms with the new Civil Procedure Code, in the reasonable duration of the process consolidated themselves as fundamental principle infra and other procedural mechanisms such as the electronic process, the procedural calendar, conciliation, and in alternative dispute resolution, such as mediation and arbitration, causing justice to be seen as a broader system, Multiport Court, presenting highly relevant in procedural legal scenario.
\end{abstract}

Keywords: Access to justice; Reasonable duration of the process; Social pacification; Conciliation. Mediation

${ }^{1}$ Doutorando em Ciências Jurídicas e Sociais pela Universidad del Museo Social Argentino, UMSA - Buenos Aires, (Argentina). Juiz de Direito. E-mail: luizfbelchiorsilva@ hotmail.com 


\section{INTRODUÇÃo}

Nos últimos tempos, diante da imagem negativa que tem passado à sociedade, de que é moroso, lento, inacessível, o Judiciário brasileiro vem passando por inúmeras reformas, visando qualificar a prestação jurisdicional, e melhorar sua imagem tão desgastada perante a sociedade brasileira.

Com a promulgação da Constituição de 1988, em que se alargou e garantiu diversos direitos sociais e fundamentais, dentre eles o acesso à justiça, aumentou gradativamente a busca pelo poder judiciário como meio de solução de conflitos sociais.

$\mathrm{O}$ acesso à justiça é compreendido como um princípio, no qual se pode destacar quatro subprincípios: acessibilidade, operosidade, utilidade e proporcionalidade. A ideologia central destes subprincípios está ligada ao terceiro movimento de acesso à justiça, trabalhado por Cappelletti, no qual se busca uma maior efetividade à ordem jurídica (OLIVEIRA, 2014, p.30).

Cappelletti;Ghart (2002, p.31) ao estudar o acesso à justiça classificou-o em ondas, sendo a primeira a assistência judiciária gratuita voltada aos pobres, a segunda a tutela dos interesses difusos e coletivos, ampliando o acesso às questões ambientais e do consumidor e a terceira onda, que é o próprio enfoque de acesso à justiça, em que buscou demonstrar que o sistema tradicional não era mais adequado, sendo preciso dar efetivo acesso dentro de uma ordem jurídica justa.

O presente estudo centra-se na discussão da terceira onda de acesso à justiça, haja vista que apresenta novos mecanismos por intermédio de procedimentos simplificados, meios eletrônicos e a apresentação dos meios alternativos de solução de controvérsias.

Gonçalves (2014, p.54) destaca ainda que no estudo do acesso à justiça Cappelletti; Ghart (2002, p.15-29) destacou três grandes grupos de obstáculos a esse direito fundamental, sendo obstáculos de ordem econômica, os relativos à desigualdade material das partes e obstáculos relativos aos entraves processuais.

Diante dessa realidade e necessidade de adequação para garantia do acesso à justiça, o Brasil ao longo dos anos tomou algumas medidas, fez reformas na legislação e adaptou sistemas, visando garantir a todos de forma indistinta o direito fundamental de acesso à justiça. 
Nesse contexto, para melhor garantir esse acesso à justiça, e ofertar de modo mais célere a resolução dos conflitos foi criado o microssistema processual dos Juizados Especiais, criando-se um ambiente menos formal, sem obrigatoriedade de advogado e sem custos na primeira fase, instalados em diversos bairros de cada localidade, visando, por certo, romper a barreira do acesso à justiça e cumprir melhor a função de pacificador social.

A Emenda Constitucional 45/2004 também representou um marco na história da justiça brasileira, em que se demonstrou uma preocupação efetiva com a demora na solução dos litígios e estabeleceu a razoável duração do processo e a celeridade como princípio constitucional fundamental. Criou-se também o Conselho Nacional de Justiça como instrumento de accountability horizontal, tendo como uma de suas metas criar meios e mecanismos de solução dos processos em curso na justiça brasileira.

Do mesmo modo, para acompanhar essa evolução da sociedade e do direito, o Código de Processo Civil, vem ao longo dos anos sofrendo diversas reformas, e a mais recente, objeto deste estudo, que culminou num Código totalmente novo, através da lei 13.105/2015 e alterações da Lei 13.256/2016, entrou em vigor em março deste ano.

Todas essas reformas visam, por certo combater a morosidade processual, um dos principais fatores de entraves do acesso à justiça.

Interessante destacar, que antes da reforma da Emenda 45/2004, haviam sido realizados diversos estudos e projetos no sentido de contribuir para a reforma e melhoria do sistema de justiça no Brasil.

A respeito, o Banco Mundial, junto a outros organismos multilaterais, havia iniciado nos anos 80 inúmeros projetos de modernização do Poder Judiciário. No relatório intitulado El sector judicial en américa latina: elementos da reforma, delineia-se com maior perfeição a visão do Poder Judiciário que deveria ser adotada por países em desenvolvimento, em busca da ampliação de investimentos estrangeiros e maior inserção no mercado internacional.

Nesse relatório constatava-se que "o Judiciário é incapaz de assegurar a resolução de conflitos de forma previsível e eficaz, garantindo assim os direitos individuais e de propriedade". Afirma também que "a reforma do Judiciário faz parte de um processo de redefinição do Estado e suas relações com a sociedade, sendo que o desenvolvimento 
econômico não pode continuar sem um efetivo reforço, definição e interpretação dos direitos e garantias sobre a propriedade" (BARBOSA, 2016 p.02).

Os técnicos do Banco Mundial deixaram claro que a reforma do Judiciário faz parte de um processo de redefinição do Estado, para reforçar o desenvolvimento econômico. Mais especificamente, "a reforma do Judiciário tem como alvo o aumento de eficiência da Justiça que atualmente não tem promovido o desenvolvimento do setor privado" (MELO FILHO, 2016, p.80).

Destacou-se a urgência em estabelecer limitação ao exercício da função jurisdicional pela base da magistratura, ampliação das Cortes Supremas e prevalência da jurisprudência sumulada das mesmas sobre as decisões das instâncias inferiores, para atingir a tão decantada previsibilidade jurídica, pois a reforma econômica requer um bom funcionamento do Judiciário, o qual deve interpretar e aplicar as leis e normas de forma previsível e eficiente. Além disso, o crescimento da integração econômica entre países e regiões demanda um Judiciário com padrões internacionais (MELO FILHO, 2016, p.81).

O Banco Mundial apontou que programas de reforma também poderiam incluir alterações nos procedimentos administrativos e nos códigos de processo, para aumentar a eficiência no processamento das demandas. Apontou ainda, como ponto básico para a reforma, a criação de mecanismos paralelos destinados à composição de litígios, a adoção de sistemas que permitam a concorrência para a prestação do "serviço judicial", sugerindo a adoção de mecanismos alternativos para solução dos conflitos, como forma de assegurar privacidade, bem como quando se tratar de litígios que envolvam grandes valores econômicos.

Consoante observa Melo Filho (2016, p.82), isso levaria à redução, na medida do possível, da participação do Estado na solução dos conflitos, dando-se preferência à composição privada, em claro favorecimento ao poder econômico. Merece ainda destaque o aspecto de que o Documento recomendava os mecanismos alternativos quando da perspectiva de derrota no sistema judiciário formal e como solução para a falta de previsibilidade desse mesmo sistema.

Nota-se que muitas dessas reformas sugeridas neste projeto apresentado pelo Banco Mundial foram implantadas ao poucos no Poder Judiciário e mais recentemente pelo novo Código de Processo Civil, como se demonstrará neste trabalho. 
Com efeito, as reformas implementadas pela Emenda Constitucional 45/2004 mudaram a forma de pensar e a cultura do judiciário, principalmente dos juízes e servidores, que passaram a se preocupar efetivamente em como ofertar uma solução condizente e em tempo razoável à tutela jurisdicional pleiteada.

Contudo, tais reformas não resolveram o problema da morosidade processual. Por outro lado, a duração excessiva no julgamento e solução dos litígios não é um fato isolado, são vários fatores que contribuem para o retardo na prestação jurisdicional, como pouca quantidade de juízes, aumento progressivo de demandas, a utilização de incidentes processuais como meio de protelar o desfecho do processo, geralmente utilizados, como descreveu Cappelletti pelos "litigantes habituais", que hoje, no Brasil, pode-se classificar como sendo as grandes empresas privadas e as pessoas jurídicas de direito público, entre diversos outros fatores (ARAÚJO, 2016, p.796).

Nesse sentido, sem dúvida, que as recentes reformas introduzidas na legislação processual, com esse novo modelo chamado de processo constitucional moderno, com carga principiológica, em que se privilegia a mediação, conciliação e outros formas de solução de conflitos, como arbitragem, em que há uma reforma nos tramites processuais visando dar celeridade ao processo, como a possibilidade da audiência antes da defesa, o julgamento parcial de mérito, o saneamento organizado do processo, o calendário processual, o processo eletrônico e sua absorção pelo texto legal, são possibilidades de mitigação dos obstáculos ao acesso à justiça, principalmente no que diz respeito à razoável duração do processo, como princípio fundamental contido no art. $4^{\circ}$ ao dispor "As partes têm o direito de obter em prazo razoável a solução integral do mérito, incluída a atividade satisfativa”.

Com isso, este trabalho tem como objetivo demonstrar como as reformas trazidas pelo Novo Código de Processo Civil, já em vigor, vão contribuir para superar alguns gargalos do sistema anterior objetivando alcançar a razoável duração do processo e obter efetividade de acesso à justiça, que nos tempos hodiernos, não pode mais ser pensado apenas como acesso ao judiciário.

Para esta análise, utilizou-se da legislação, doutrina e jurisprudência, como primado normativo, fazendo um contexto histórico das mudanças no Poder Judiciário através da Emenda Constitucional 45/04 bem como das reformas processuais, especialmente no tocante ao princípio da razoável duração do processo, estabelecido em seu artigo $5^{\circ}$, inciso LXXVIII 
da Constituição Federal e no artigo $4^{\circ}$ do Novo Código de Processo Civil, com a finalidade de melhor demonstrar a temática abordada.

Neste trabalho aplicou-se o método dedutivo, enfatizando a pesquisa bibliográfica e documental, de forma explicativa, a partir da leitura de CAPPELLETTI; GARTH, MANCUSO $(2002,2015)$ bem assim como uma análise sobre a legislação brasileira, máxime o novo Código de Processo Civil, seus princípios processuais, em especial aqueles afetos à melhoria do acesso à justiça, com destaque para as principais mudanças processuais, que representam uma esperança para romper a barreira do acesso à justiça através da conciliação e de outras formas consensuais de solução de conflitos, como mediação e arbitragem, as quais serão analisadas neste trabalho.

\section{AS REFORMAS DO PODER JUDICIÁRIO: PREOCUPAÇÃO COM A RAZOÁVEL DURAÇÃO DO PROCESSO}

É difícil falar em reforma do judiciário sem mencionar a importância e o marco potencial e não se remeter a uma narrativa histórica da Emenda Constitucional 45/2004, que introduziu as mais importantes reformas para viabilizar o acesso à justiça.

A Reforma mais importante do Judiciário brasileiro foi implantada a partir da Emenda Constitucional $\mathrm{n}^{\circ} 45$, de dezembro de 2004, alterando o artigo $5^{\circ}$ da Constituição Federal, inserindo no ordenamento jurídico novos princípios como a celeridade processual, a razoável duração do processo, trazendo importantes renovações no âmbito do sistema judiciário brasileiro, cujo objetivo seria o aumento da transparência e eficiência do Judiciário, e maior grau de segurança jurídica (MENDES, 2012, p.31).

A EC 45/2004 abrangeu uma "grande reforma" do Poder Judiciário com inovações na estrutura organizacional com a criação do Conselho Nacional de Justiça. As modificações do Poder Judiciário foram significativas e impulsionaram as transformações que se seguiram nos tribunais a fim de melhorar a prestação jurisdicional e implicaram em mudanças estruturais e de mentalidade tanto dos operadores quanto do jurisdicionado.

Destaque-se que antes da Reforma do Judiciário implantada pela Emenda Constitucional 45/2004 a atuação do Judiciário era bastante deficiente. Necessitava de política pública, clara, transparente, objetiva, desde a mudança de cultura dos servidores e dos próprios magistrados, como mudança técnica no desempenho das atividades, através de 
treinamentos, cursos de qualificação, mudanças no sistema de informática, e por obvio, mudança também na legislação.

Nota-se que desde a proclamação da Constituição de 1988, em que se garantiu uma carta de direitos fundamentais, dentre eles o acesso à justiça, foram realizadas reformas tanto administrativas, constitucionais, como processuais que foram sendo introduzidas no sistema jurídico e de gestão, para a garantia desse acesso.

Os Juizados Especiais Cíveis e Criminais, criados em 1995 também representaram significativa mudança na sociedade e importante avanço para o acesso à justiça, principalmente para as camadas mais pobres da população, em vista o grau de informalidade e o fácil acesso, a desnecessidade de advogado, a dispensa de pagamento de custas, conferindo mais cidadania e acesso à classe menos favorecida.

A propósito, como observa Annoni (2008, p.260), os Juizados Especiais se tornaram a principal porta de acesso à justiça para a maioria da população brasileira, especialmente para reclamações de relações de consumo, reguladas pelo Código de Defesa do Consumidor, promulgado em 1990.

Do mesmo modo, os Juizados Especiais Cíveis e Criminais no âmbito da Justiça Federal, criados em 2001, através da Lei no 10.259, ampliou o acesso à justiça, principalmente para as questões previdenciárias.

Posteriormente, em 2009, ampliando ainda mais o microssistema dos Juizados Especiais, foram criados os Juizados Especiais da Fazenda Pública, no âmbito dos Estados, Distrito Federal e Municípios. Esses sistemas, menos formais, orientados pelos princípios da oralidade, simplicidade, informalidade, economia processual e celeridade, em que a conciliação e transação também são buscadas prioritariamente, representam importante meio de acesso ao cidadão na busca de seus direitos.

Buscando acompanhar a evolução e as necessidades, a Emenda Constitucional no 19 de 1998, modificou o artigo 37 da CF dando status constitucional ao princípio da eficiência na administração pública ao dispor "A administração pública direta e indireta de qualquer dos Poderes da União, dos Estados, do Distrito Federal e dos Municípios obedecerá aos princípios de legalidade, impessoalidade, moralidade, publicidade e eficiência” (BRASIL).

No mesmo sentido, atento às mudanças sociais, o judiciário vem estabelecendo metas, se adaptando às novas tendências, modelando sua estrutura em seu aspecto material, 
para atender ao movimento evolutivo da sociedade e, principalmente, para melhor acolher as demandas e litígios que lhe são postas, dentro de uma realidade mais dinâmica e efetiva.

Com efeito, a EC/45/2004 ao estabelecer o princípio da razoável duração do processo, art. artigo $5^{\circ}$ LXXVIII, da Constituição "a todos, no âmbito judicial e administrativo, são assegurados a razoável duração do processo e os meios que garantam a celeridade de sua tramitação", preocupando-se com o tempo do processo e a celeridade de sua tramitação, trouxe enorme contribuição para a ciência processual.

Constata-se que o acesso à justiça, como destaca Costa (2016, p.258), tem uma dimensão substancial de "transformação social pela efetivação de direitos e tem também uma dimensão procedimental, relacionada à ampliação, racionalização e controle do aparato (instituições e procedimentos) governamental de realização de direitos".

Assim, na busca de tornar o judiciário menos moroso e mais eficiente foram implantadas grandes reformas, Emendas à Constituição, reforma na estrutura e funcionamento do Judiciário através da EC 45/2004, mudanças legislativas, através de várias reformas no Código de Processo Civil de 1973 e outras legislações infraconstitucionais.

Porém, tais inovações não foram suficientes para amenizar o problema do acesso à justiça, principalmente na primeira instância, que é mais próxima do jurisdicionado, assim como da celeridade e eficiência da prestação jurisdicional (HESS, 2010, p. 216).

Quer dizer, o Poder Judiciário não conseguiu alcançar esse ideal de justiça, de modo a ofertar uma rápida e eficaz solução de conflitos, e passou nos últimos tempos a ser objeto de estudo da sociologia jurídica e de debate na agenda dos Tribunais Superiores, nas academias e na sociedade.

Muitos são os gargalos que impedem essa efetividade, como poucos magistrados, servidores despreparados, o litiganismo desenfreado e a crise numérica de processos, fatores esses que contribuem inexoravelmente para a morosidade processual.

Esse litiganismo recorrente encontrou o Judiciário com uma estrutura despreparada para processar e julgar as causas no tempo necessário, pois a constância e a intensidade das mudanças sociais são maiores do que as condições de adaptação da organização e estrutura das instituições públicas (PONCIANO, 2015, p.01).

Ainda nesse contexto, a morosidade da justiça é inegável e vem sendo apontada como grave problema enfrentado pelo judiciário brasileiro, evidenciada a partir do advento da Constituição Federal de 1988, pois, ao garantir o acesso à justiça e ampliar o rol dos direitos 
fundamentais, abriu caminho para uma corrida em massa ao Judiciário de várias demandas sociais. Isso gerou um aumento considerável da quantidade de processos e, consequentemente, da taxa de congestionamento desses processos sem que o Judiciário estivesse preparado para essa realidade (PONCIANO, 2015, p.01).

Assim, a constatação da ineficiência da atuação Estatal em dar cumprimento a esse direito fundamental do cidadão deixou mais evidente a necessidade de ações convergentes para solucionar o problema do acesso à justiça. Nesse contexto, conforme destaca Grangeia (2013, p.17), as readequações estruturais do Poder Judiciário surgem como opção plausível para tornar realidade esse acesso, de forma inclusiva, democrática e abrangente.

Desde a década de 1990, Grinover (1990, p.177) já sustentava o descompasso entre doutrina, legislação e prática judiciária, que o aparelho judiciário não correspondia ao avanço cientifico da norma, a sobrecarga dos tribunais, a morosidade e emperramento da burocratização da justiça levava a uma obstrução do acesso à justiça, via de consequência à demora na solução das demandas.

Conforme destacou Mancuso (2011, p.211) é evidente que se não for feito um remodelamento no Judiciário, a crise, que é a enorme quantidade de processo sem resolução nos Tribunais, tende só a se agravar mais, sendo preciso que sejam tomadas providencias corajosas e eficazes, que deem conta de reestruturar todo o sistema. Essa política perpassa por uma melhor administração do Judiciário, mas principalmente por uma melhor harmonia e seriedade entre os Poderes.

$\mathrm{Na}$ verdade, função jurisdicional do Estado somente se justifica e se legitima na medida em que possa ofertar uma resposta de qualidade, a saber, revestida de seis atributos: justa, jurídica, econômica, tempestiva, razoavelmente previsível e idônea a assegurar a fruição efetiva do direito, valor ou bem da vida reconhecidos no julgado (MANCUSO, 2011, p.214).

A necessidade de respeito à duração razoável do processo decorre dos anseios de uma sociedade dinâmica, centrada na tecnologia da informação, cuja maioria das relações ocorre em tempo real. A sociedade não concebe que no mundo moderno, em que é possível enviar informações de uma parte a outra do planeta instantaneamente, a justiça não possa acompanhar essa modernidade e que o processo não atinja sua finalidade num tempo razoável (PONCIANO, 2015, p.01). 
Muito embora o conceito de razoável duração do processo não fixe medida temporal, a eficiência é comando a ser aplicado em atenção às peculiaridades do processo, de modo a evitar tempo vago para soluções sobre o direito em razão de formalismos ou expedientes desnecessários, o chamado tempo morto do processo.

O direito fundamental à razoável duração do processo, como observado por Toaldo (2016, p.05), é um direito especial, tendo em vista que determina que sejam especificadas limitações no correr do desenvolvimento processual, para que seja buscada a forma mais célere para a composição do litígio.

Mas, a razoabilidade da duração do processo depende também da perspicácia do juiz proativo na condução do processo, com a finalidade de buscar meios de solucionar o processo, ou seja, a melhoria na prestação jurisdicional "depende de um juiz ajustado ao tempo do processo, comprometido com realização do justo, apesar das deficiências materiais e a carga irracional de trabalho" (HESS, 2010 p.220).

Importante destacar que na busca de encontrar soluções eficazes para essa problemática, sem dúvida, que o novo código pretende superar alguns desses gargalos do sistema anterior e, na medida do possível, abreviar o tempo do processo.

A Carga principiológica do Novo Código de Processo Civil consagra a aplicação de direitos e garantias fundamentais, como razoável duração do processo, igualdade de tratamento e isonomia entre as partes, ao estabelecer no art.4 "As partes têm o direito de obter em prazo razoável a solução integral do mérito, incluída a atividade satisfativa", e ainda, art. $7^{\circ}$ "É assegurada às partes paridade de tratamento em relação ao exercício de direitos e faculdades processuais, aos meios de defesa, aos ônus, aos deveres e à aplicação de sanções processuais, competindo ao juiz zelar pelo efetivo contraditório", demonstrando a valorização dessas garantias e a positivação infraconstitucional dos direitos fundamentais processuais.

Esse ambiente de positivação de princípios, solidificados como regras claras, condutoras do processo civil brasileiro, formando um arcabouço de normas que, se interpretadas de maneira realmente integrativa, servirão para mitigar as dificuldades hodiernas do judiciário, torna possível focar no recrudescimento de métodos e procedimentos que tenham como escopo razoabilizar a duração dos processos e promover a conciliação.

\section{A RAZOÁ VEL DURAÇÃO DO PROCESSO E AS REFORMAS DO CÓDIGO DE PROCESSO CIVIL}


A tempestividade na prestação jurisdicional é uma das principais preocupações do direito atualmente, pois uma lide que se rasteja por anos traz revolta e indignação para quem espera por uma resolução do litígio de forma mais célere possível (GONÇALVES, 2014, p. 91).

A propósito, como observa Annoni (2008, p.245), o Brasil ratificou a convenção Americana de Direitos Humanos em 1992, incorporando-a ao ordenamento jurídico interno, por meio do Decreto 678/92, tornando-se responsável pela efetivação dos direitos ali consagrados, contemplando dentre eles, o direito à prestação jurisdicional dentro de um prazo razoável.

Contudo, o direito fundamental da razoável duração do processo ingressou efetivamente no ordenamento jurídico e foi alçado ao rol de direito constitucional como princípio fundamental através da Emenda Constitucional 45/2004, que inseriu na Constituição Federal o art. $5^{\circ}$, inc. XXXV, ao dispor: "a lei não excluirá da apreciação do Poder Judiciário lesão ou ameaça de direito". Mas não basta simplesmente garantir o simples acesso ao judiciário, é necessário que se busque efetivá-lo (GONÇALVES, 2014, p. 93).

A positivação do princípio da razoável duração do processo, que está no rol dos direitos fundamentais, demonstra a latente importância e necessidade do Poder Judiciário criar meios e mecanismos para adequação da realidade jurídica em destaque.

Nesse contexto, pode-se afirmar que a morosidade da justiça é um dos mais recorrentes e atuais problemas que envolvem o Poder Judiciário, não só do Brasil, mas de boa parte do mundo. Porém, como destaca Gonçalves (2014, p.100), no Brasil, essa problemática vem atingindo níveis alarmantes, gerando consequências sociais críticas e "traz graves restrições ao direito de cidadania para grande parcela do país, em especial para os hipossuficientes".

Dessa forma, é necessário que a solução da lide seja obtida em tempo hábil, com tutela adequada, consoante observa Watanabe (1988, p.34), pois não se pode pensar em acesso à justiça apenas como acesso ao judiciário, o conceito de acesso à justiça representa acesso à ordem jurídica justa, em tempo razoável.

Como destaca Pereira Filho $(2015$, p.38) a luta por um tempo razoável, ideal, não pode prescindir da efetividade, pois "processo rápido, mas não efetivo equivale à morosidade 
agravada pela desilusão do ganhar, mas não levar”, ou seja, a duração razoável do processo não implica em rapidez, mas precisa de um contraditório efetivo, eliminando-se atos processuais desnecessários. Nesse sentido, duração e efetividade do processo são balizas que devem ser alcançadas simultaneamente.

Numa outra ordem de ideias, não se pode pensar também somente num ambiente de judicialização, de litigiosidade, é preciso que a procura pela justiça seja realizada de modo responsável, como último recurso a ser utilizado. Existem outras formas de solução de controvérsias, tais como o diálogo entre os pretensos litigantes, o fomento de uma cultura de pacificação social, onde a litigiosidade é mitigada pelo desejo de conciliar, dentre outras implementações de consciência, tais como ouvidorias de órgãos públicos, prestadores de serviços, muito bem estruturadas, onde o cidadão pode resolver seus conflitos sem ter de recorrer ao Poder Judiciário.

Outras práticas positivas voltadas para a minoração do ambiente de litiganismo no Direito Brasileiro é o fortalecimento de órgãos administrativos de fiscalização e resolução dos conflitos consumeristas, situação em que a busca pela satisfação pessoal em ter um problema resolvido, um produto devolvido, um serviço não prestado ressarcido, deva ser maior do que a busca pelo caráter indenizatório/reparatório na esfera judicial.

Nesse sentido, como observa Gonçalves (2014, p.227) e Mancuso (2015, p. 298) é necessário impedir que o direito de ação converta-se num dever de ação, passando ao jurisdicionado a ideia falaciosa de que todo e qualquer conflito deva redundar num processo judicial, em virtude de uma interpretação atécnica e irrealista da garantia de acesso à justiça.

Mancuso (2015, p.289) alerta que o volume excessivo de processos não está na origem dos males, mas antes é a consequência sustentada por uma ideologia irrealista do acesso à justiça, como se fosse uma interpretação equivocada pelo cidadão da garantia do acesso à justiça, "com isso fomentando a contenciosidade ao interno da coletividade e desestimulando as outras formas, auto e heterocompositivas de solução de controvérsias".

Isso decorre por falta de informação quanto aos outros meios, ditos alternativos de auto e heterocomposição de litígios, ainda pela cultura de que a sentença como solução imperativa tem mais força porque representada pelo Estado, passando a ideia de que isso representa manifestação de cidadania, o que acaba por retroalimentar a demanda (MANCUSO, 2015, p.62) 
No contexto atual, em que a litigiosidade virou regra e não exceção gerou uma crise numérica de processos que a justiça brasileira não está conseguindo suportar, isso porque não se tem estimulado os meios alternativos de solução de controvérsias. Isso precisa ser revisto, essa cultura precisa ser mudada.

Os números apresentados pelo relatório do CNJ são alarmantes ${ }^{2}$. Mas essa realidade não é culpa do cidadão e do mesmo modo, esse fato não pode ser motivo para se fechar as barreiras do acesso à justiça, pois muito dos fatores da busca desenfreada pela justiça é decorrente da falta de comprometimento das empresas privadas que descumprem acordos e contratos firmados e às vezes da própria justiça que colabora para esse ambiente de judicialização quando fixa indenizações de baixo valor estimulando esse comportamento leniente das empresas, contribuindo para a repetição da conduta danosa ao consumidor.

Contudo, abandonando um pouco o ambiente de críticas, faz-se necessário destacar que o novo Código de Processo Civil trouxe importantes alterações. A nova égide normativa que reformou o Processo Civil Brasileiro trouxe inovações, principalmente na ordem dos princípios norteadores do processo, como o da cooperação, da celeridade e da conciliação. Sobre este último houve um regramento próprio, com a prioridade da composição consensual sobre a litigiosidade.

O parágrafo $3^{\circ}$, do artigo $3^{\circ}$ do Código de Processo hoje em vigor estabelece que " $\mathrm{A}$ conciliação, a mediação e outros métodos de solução consensual de conflitos deverão ser estimulados por juízes, advogados, defensores públicos e membros do Ministério Público, inclusive no curso do processo judicial". Nasce aqui a composição não apenas como uma consequência da instauração do litígio, como elemento orientador da resolução de conflitos, mas sobrepujante à decisão judicial, voltando à realização da pacificação social sobre a disposição verdadeira das partes em chegar ao encontro de vontades.

\footnotetext{
${ }^{2}$ Gráfico da Litigiosidade: Em 2014, o Poder Judiciário iniciou com um estoque de 70,8 milhões de processos, que tende a aumentar devido ao total de processos baixados ter sido inferior ao de ingressados (Índice de Atendimento à Demanda - IAD de 98,7\%). Estima-se, portanto, que ao final de 2014 o estoque cresça em meio ponto percentual, ultrapassando, assim, 71,2 milhões de processos pendentes. Apesar deste cenário, desfavorável, houve aumento de $1,4 \%$ no total de processos baixados e que representa cerca de 28,5 milhões de processos em 2014. Já o número de casos novos aumentou em $1,1 \%$, atingindo quase 28,9 milhões de processos ingressados durante o ano de 2014 (Gráfico 3.14). Como consequência do aumento do quantitativo de casos novos e de pendentes, a Taxa de Congestionamento do Poder Judiciário foi de 71,4\% no ano de 2014, com aumento de 0,8 pontos percentuais em relação ao ano anterior.
} 
Esse norte do hodierno processo civil por si só já configura alvíssaras para a ampliação do acesso à justiça e em favor da busca pela redução do tempo do processo na resolução dos litígios. Essa nova ordem processual vai ao sentido contrário à doutrina de Couture (2008, p.27), que elenca a ação como direito de petição assegurada constitucionalmente, uma vez que não é só a decisão que coloca termo ao conflito, mas, principalmente o acordo, nesse caso, obtido através da Conciliação, da Mediação ou da Arbitragem.

A criação de Centros de Conciliação, Mediação conduzidos por magistrados, com funcionamento vinculado aos Tribunais de Justiça, consiste numa excelente ferramenta que travará uma disputa com o comportamento atávico do brasileiro em ser naturalmente litiganista.

A arbitragem como elemento de pacificação, também é uma ferramenta que apresenta uma solução em tempo rápido e de forma bastante eficaz.

O Conselho Nacional de Justiça com a implantação do chamado Tribunal Multiportas através da Resolução 125/2010, passou a oferecer ferramentas para tratamento amistoso de controvérsias, criou Núcleos e Centros Judiciários de Solução de Conflitos e Cidadania (CEJUSC), estimulando a pacificação social, através de maneiras autocompositivas e heterocompositivas, agora positivadas na legislação processual em vigência.

Os princípios fundamentais infraconstitucionais representam importante avanço ao processo constitucional, dentre os quais se destacam o da razoável duração do processo, da cooperação, da primazia do julgamento do mérito e essas alterações processuais se estendem para a sociedade, como importante passo ao ideário de uma justiça mais célere e mais dinâmica.

O princípio da razoável duração do processo consagrou também o princípio da primazia do julgamento do mérito, em que o julgador, sempre que possível, deve priorizar o julgamento do mérito, superando os vícios processuais e o quanto possível aproveitando todos os atos do processo, tudo isso com observância do contraditório e do devido processo legal.

O princípio da cooperação, importado do direito europeu é um produto da atividade triangular, entre o juiz e as partes. Esse dever de colaboração é eminentemente voltado para o magistrado no sentido de orientar e colaborar com sua participação no processo. Decorrente dessa atividade processual cooperativa, o juiz tem o dever de esclarecimento, de consulta, de 
prevenção, de auxílio e de urbanidade, adotando conduta ética e respeitosa em sua atividade judicante (DONIZETTI, 2016, p.43).

Como salienta Marinoni (2016, p.79) o processo agora é visto como uma comunidade de trabalho regida pela ideia de colaboração, em que o juiz "tem o dever de cooperar com as partes a fim de que o processo civil seja capaz de chegar efetivamente a uma decisão justa, fruto de um diálogo efetivo, mais franco, aberto e ponderado", como idealizado nos arts. $6^{\circ}, 7^{\circ}, 8^{\circ}, 9^{\circ}$ e $10^{\circ}$ do novo Código, portanto, há um "efetivo dever de engajamento do juiz no processo".

Outra possibilidade é o estabelecimento do calendário processual para a pratica dos atos processuais, previsto no artigo 191 do CPC, modelo já existente no direito francês, italiano e inglês. A vantagem do calendário procedimental é que após as partes fixarem as datas no calendário processual, não será necessária a intimação das partes para a prática do ato processual ou realização de audiência. É uma forma de diminuir o trabalho da serventia judicial e consequente eliminação de tempo morto, evitando também alguma eventual nulidade formal na intimação (NEVES, 216. p.191).

Esse instituto já vem sendo aplicado com sucesso em outros países e na realidade da processualística brasileira, como observa Neves (2016, p.191), não se pode negar o avanço que isso representa para a celeridade, efetividade e eficiência do processo, princípios consagrados no art. $8^{\circ}$ do Código de Processo Civil, além de proporcionar maior segurança jurídica, em razão da elevada previsibilidade da duração do processo nessa modalidade.

Segurança jurídica e efetividade são elementos indispensáveis para o fortalecimento do judiciário e sua consolidação enquanto instituição. A partir do momento, agora, em que esses macro princípios se tornam normas explícitas para determinar o norte do processo civil brasileiro, há uma sintomática sensação de justiça na sociedade, ampliando, sem dúvida, o acesso à justiça, que, adiante, poderá promover maior pacificação social.

Não se pode limitar-se apenas ao retórico universo abstrato das críticas sobre o acesso à justiça no sistema processual brasileiro, sendo necessário buscar efetivas e pragmáticas soluções, tais como essas aqui mencionadas, para que a razoável duração dos processos seja de fato uma realidade, que seja possível a sensação de paz social causada pelos êxitos conciliatórios e que traga com isso uma melhor distribuição de direitos e deveres. 
O artigo 165, do Novo Código de Processo Civil é bem firme ao determinar que "Os tribunais criarão centros judiciários de solução consensual de conflitos, responsáveis pela realização de sessões e audiências de conciliação e mediação e pelo desenvolvimento de programas destinados a auxiliar, orientar e estimular a autocomposição” (BRASIL, 2016).

Advogados, juristas, professores de Direito e, principalmente, os Magistrados e membros do Ministério Público Brasileiro devem se envolver bastante para que esses centros sejam instaurados, onde exercerão suas atividades pessoas altamente treinadas e preparadas para lidar com toda sorte de conflitos e agindo de forma profícua para a obtenção do resultado homologado pelo consenso.

Quanto mais centros de conciliação, mediação e arbitragem estiverem funcionando de forma realmente proativa e exitosa, mais rápida será a entrega da prestação jurisdicional e a sensação de resolução de problema. Está aqui um norte para a democratização do acesso à Justiça através da estimulação da consensualidade, imprimindo maior celeridade ao processo civil brasileiro.

Outro elemento que contribui hoje para recrudescer o sistema é a tecnologia. Ora, existe uma série de recursos tecnológicos que podem contribuir para a redução do tempo de tramitação dos processos, realizando a justiça temporalmente mais razoável.

Isso porque audiências podem ser claramente realizadas pelo sistema de teleconferências, ou que depoimentos tomados em outras comarcas podem ser remetidos como arquivos de vídeos através de sistema eletrônico de tramitação de autos. Isso dispensaria, por exemplo, a emissão de cartas precatórias, considerando o longo tempo que elas em regra levam para ser cumpridas, pois a demora no cumprimento de uma carta precatória entre uma comarca de capital e outra de interior tem a capacidade de atrasar a tramitação de um processo por um período próximo de um ano, o que pode ser reduzido em dias, caso englobassem diversos atos processuais em sistemas eletrônicos, vídeos, arquivos virtuais, as chamadas "nuvens".

O Novo Código de Processo Civil consolidou o processo eletrônico como realidade no sistema brasileiro, não só no escólio de seu artigo 193, segundo o qual "Os atos processuais podem ser total ou parcialmente digitais, de forma a permitir que sejam produzidos, comunicados, armazenados e validados por meio eletrônico, na forma da lei”, mas em todo texto da Lei n. 13.105/2015 há referências para que sejam priorizados os meios eletrônicos de armazenamento e execução dos atos processuais (BRASIL, 2016). 
Demais disso o processo judicial eletrônico já foi implantado em $80 \%$ dos Estados brasileiros, situação que deverá ser ampliada, melhorada, valorizada. Necessário que haja uma conscientização tanto do Poder Legislativo, quanto do Executivo para pensarem em recursos que sejam suficientes para financiar as renovações do Judiciário, condição essencial para melhorar a sociedade de hoje.

A realidade, por exemplo, das audiências em teleconferências, ou então gravadas em arquivos de vídeo significa um sensível ganho temporal apto a incrementar o sistema e promover uma entrega da prestação jurisdicional mais célere, acessiva e qualitativa, do ponto de vista material.

Ocorre que para a efetivação de certos serviços e procedimentos é necessário que haja uma melhoria no fornecimento de acesso à internet, principalmente se tendo em conta comarcas de lugares remotos, lotados em municípios precários de equipamentos públicos, com comunicação deficitária. Observa-se que a análise das inovações processuais transcendem os conceitos apenas jurídicos. Nesse aspecto, o Novo Processo Civil Brasileiro precisa ser aprimorado, adequando-se ainda mais à nossa realidade e necessidade.

De modo geral, óbvio que por mais que se normatize os fundamentos do processo civil brasileiro, não haverá resultados em curto prazo, sem que haja um elemento fundamental, condição sine qua non para a efetivação do Novo Código de Processo Civil, ou seja, não haverá aprimoramento do sistema sem que haja real conscientização de todos os atores envolvidos no litígio, incluindo aqueles capacitados para trabalhar em favor de sua solução, advogados, magistrados, serventuários, Ministério Público, árbitros, mediadores, fiscais dos limites das atividades privadas, regulamentadores do serviço público, dentre outros.

E é através desse processo evolutivo, com a proeminência do Novo CPC, que se buscará fortalecer o instituto do acesso à justiça, desvinculando a visão de que Justiça somente possa ser obtida através de decisões judiciais, quando, na verdade, Justiça deve consistir, essencialmente, num estado de espírito, num sentimento vivenciado por quem dela precisa.

\section{CONCLUSÃO}


Seguramente, quanto maior a possibilidade de se aceder à Justiça, quanto mais possível for exercer o direito constitucional de petição, mais a sociedade terá seus pilares consolidados, suas instituições mais fortalecidas, recrudescendo seus fundamentos constitucionais, republicanos e democráticos.

E foi pensando justamente na necessidade de se adequar a norma processual à realidade atual, bem posterior ao antigo diploma processual, datado de 1973, que se concebeu o Novo Código de Processo Civil, Lei n. 13.105/2015, onde se buscou normatizar procedimentos, princípios, condutas, métodos e comportamentos, sempre visando em três aspectos principais: acesso à justiça, resolução efetiva de litígios e razoável duração dos processos.

Mas não é só. Não se pode pensar que o Novo Código veio especificamente para acelerar o processo. Na realidade é um conjunto de medidas que vai aos poucos solucionar essa problemática da morosidade processual. O processo eletrônico, por exemplo, a melhor adequação dos servidores, com capacitação, a Mediação e Conciliação como fase inicial ou pré-processual, a Arbitragem, todos esses mecanismos vão contribuir para o término dos processos, inclusive os físicos, e aos poucos vai se aperfeiçoando o processo judicial eletrônico, uma ferramenta que vai contribuir muito para melhoria do sistema.

Consoante aqui já dito, somente com uma real e efetiva conscientização de todos os atores envolvidos na busca pela solução de qualquer litígio, ou seja, partes, advogados, magistrados, serventuários, é que se poderá alcançar uma solução mais justa, rápida, segura e efetiva possível da verdadeira Justiça.

É, de plano, realmente necessário que se ponha freio sobre a cultura do litiganismo, tão evidente no sistema jurídico brasileiro, fomentado desde as Faculdades de Direito, criando, desde então, uma educação ao futuro jurista voltada à solução efetiva e não à disputa.

Isso porque, há, por exemplo, a solução consensual, onde o diálogo surge como ponto de partida, que se terá, em tese, a melhor entrega da Justiça ao cidadão, pois onde há uma concessão mútua de necessidades e pretensões, mais se estará próximo do sentimento abstrato de Justiça.

Devem-se buscar outros meios alternativos de solução de controvérsias, a Conciliação e a Mediação, de modo a ampliar de fato o acesso à justiça, facilitando o cumprimento dos princípios hoje tipificados no Código de Processo Civil Brasileiro. A partir do momento em que princípios como razoável duração do processo, segurança jurídica e 
efetividade se tornam positivados dentro da formalidade legal do processo, mais consistente se torna a solução do litígio e mais amplo o acesso à justiça.

Vive-se, no momento, a era da desjudicializaçao, quando o sistema judiciário não suporta mais a sobrecarga de processo. Na verdade, atualmente o Brasil vive uma crise nos três poderes, e o Poder Judiciário vive uma crise numérica de processos, o relatório do CNJ mostra isso.

É preciso valorizar esse Tribunal Multiportas, essas outras formas de pacificação de conflitos, Conciliação, Mediação e Arbitragem. O Tribunal Multiportas é uma instituição inovadora que direciona os processos que chegam a um tribunal para os mais adequados métodos de resolução de conflitos, economizando tempo e dinheiro tanto para os tribunais quanto para os participantes ou litigantes, representando novas perspectivas de acesso à justiça.

Dinamarco (2009, p.58), potencializa a celeridade e eficiência do curso processual. Segundo ele, a jurisdição é a atividade de pacificação social das partes, especialmente no tocante aos meios alternativos de solução de controvérsias, que representam avanço para melhoria do acesso à justiça que não pode ser visto apenas como ingresso em juízo.

Busca-se a mitigação dos obstáculos que sobrecarregam o funcionamento da justiça brasileira, que encontra paradigmas e algumas experiências exitosas na hodierna ótica cívelprocessual registrada no Novo Código de Processo Civil, em vigor desde março de 2016.

Tal como observa Mancuso (2011, p.339), para que o acesso à justiça seja devidamente percebido como uma perspectiva realista, voltado à realidade contemporânea, não se pode prometer uma solução exagerada, a qual o Estado não conseguiria atender. $\mathrm{O}$ aprimoramento do sistema não se concebe sem recursos, sem incentivos e sem conscientização da sociedade.

Encerra-se com a positiva avaliação de que o Novo Código de Processo Civil trará, sim, êxito no aprimoramento na solução de conflitos, seja através do Judiciário tradicional, seja através de câmaras de Mediação, Arbitragem, Centros de Solução Litígios, intermediação legalizada, prevendo-se recursos públicos para o incremento do processo eletrônico, recriando a realidade da atividade jurisdicional civil, reduzindo o prazo para a entrega dessa prestação, ao mesmo tempo em que se busca oferecer a melhor qualidade na solução desses litígios, promovendo a mais satisfatória sensação de verdadeira e possível Justiça. 


\section{REFERENCIAS}

ANNONI, Danielle. O direito Humano de Acesso à Justiça no Brasil. Porto Alegre: Sérgio Antonio Fabris Editor, 2008.

ARAÚJO, José Henrique Mousa. A duração razoável do processo e o fenômeno da coisa julgada no Novo Código de Processo Civil. In: DIDIER JR, Fredie (Org.). Coleção Novo CPC. Doutrina Selecionada 2. Procedimento Comum. $2^{\mathbf{a}}$ ed. Salvador: Editora Jus Podivm, 2016.

BARBOSA, Claudia Maria. Poder Judiciário: reforma para quê? Disponível em: <http://www.ambitojuridico.com.br/site/index.php?n_link=revista_artigos_\%20leitura\&artigo _id=2339>. Acesso em: 07 set 2016.

BRASIL. Constituição da República Federativa do Brasil de 1988. Diário Oficial da União da República Federativa do Brasil. Disponível em: http://www.planalto.gov.br/ccivil_03/constituicao/constitui\%C3\%A7ao.htm. Acesso em: 23 agos. 2016.

Lei $n^{0}$ 13.256, de 4 de fevereiro de 2016. Diário Oficial da União da República Federativa do Brasil. Disponível em: http://www.planalto.gov.br/ccivil_03/leis/15869.htm.24 agos. 2016.

. Conselho Nacional de Justiça. Disponivel em: http://www.cnj.jus.br. 03 set 2016.

CAPPELlETTI, Mauro; GARTH, Bryant. Acesso à Justiça. Tradução Ellen Gracie Northfleet. Porto Alegre: Fabris, 2002.

COSTA. Susana Henriques da. Acesso à justiça: promessa ou realidade? Uma análise do litígio sobre creche e pré-escola no Município de São Paulo. In: PUOLI, José Carlos Baptista (Org.). Direito Processual Constitucional. Brasília. Editora Gazeta Jurídica, 2016.

COUTURE, Eduardo. Introdução ao Estudo do Processo Civil. São Paulo: Lider: 2008.

DINAMARCO, Candido Rangel. A instrumentalidade do processo, 14 a ed.Sao Paulo: Malheiros, 2009.

DONIZETTI, Elpídio. Curso didático de direito processual civil. 19a ed. São Paulo: Atlas, 2016.

GONÇALVES, Vinícius José Corrêa. Tribunais multiportas: pela efetivação dos direitos fundamentais de acesso a justiça e a razoável duração dos processos. Curitiba: Juruá, 2014.

GRANGEIA, Marcos Alaor Diniz. A crise de gestão do Poder Judiciário: O problema, as consequências e os possíveis caminhos para a solução. Disponível em: <http://www.enfam.jus.br/wp-content/uploads/2013/01/2099_Des

_Marcos_Alaor_Artigo_ENFAM_28_4_2011_editado.pd>. Acesso em: 26 set 2016. 
GRINOVER, Ada Pellegrini et al., Código brasileiro de defesa do consumidor comentado pelos autores do anteprojeto, vol.II, 10ª ed.Rio de Janeiro, Forense, 2011.

HESS, Heliana Coutinho. O Princípio da Eficiência e o Poder Judiciário. Disponível em: <http://www.revistas.usp.br/rfdusp/article/viewFile/67899/70507>.Acesso em: 25 set 2016.

MANCUSO, Rodolfo de Camargo. Acesso à Justiça. São Paulo. RT. 2015. Acesso à Justiça. São Paulo. RT. 2011.

MARINONI, Luiz Guilherme; ARENHART, Sérgio Cruz; MITIDIERO, Daniel.Curso de Processo Civil. Teoria Geral do Processo. V.1 $2^{\mathrm{a}} \mathrm{ed}$. revista e atualizada. São Paulo: Editora Revista dos Tribunais, 2016.

MELO FILHO, Hugo Cavalcanti. A Reforma do Poder Judiciário Brasileiro: motivações, quadro atual e perspectivas. Disponível em: <http://www.jf.jus.br/ojs2/index.php/revcej/article/viewFile/551/731>. Acesso em: 07 set 2016.

MENDES, Gilmar. Organização do Poder Judiciário Brasileiro . Disponível em: < http://www.stf.jus.br/arquivo/cms/noticiaArtigoDiscurso/anexo/JudicBrasil.pdf >. Acesso em: 20 set 2016.

NEVES, Daniel Amorim Assumpção. Novo Código de Processo Civil comentado artigo por artigo. De acordo com a Lei 13.256, de 04.02.2016 altera o Novo CPC - Processo do RE e REsp.Salvador: EditoraJuspodivm, 2016.

OLIVEIRA, Emerson Ademir Borges de. Ativismo Judicial e controle de constitucionalidade: impactos e feitos na evolução da democracia. Curitiba: Juruá, 2015.

PEREIRA FILHO, Benedito Cerezzo. A Duração Razoável do Processo na Perspectiva do Novo Código de Processo Civil - Lei n ${ }^{\circ} 13.105$, de 16 de março de 2015. In: O Novo Código de Processo Civil. Questões Controvertidas. Vários autores. São Paulo: Editora Atlas, 2015.

PONCIANO, VERA LUCIA FEIL. Controle da Morosidade do Judiciário: Eficiência só não Basta. Disponível em: < http://www.ibrajus.org.br/revista/artigo.asp?idArtigo=346>. Acesso em: 26 set 2016.

TOALDO, Adriane Medianeira. A razoável duração do processo frente à efetividade e a celeridade da tutela jurisdicional. In: Âmbito Jurídico, Rio Grande, XII, n. 68, set 2009. Disponível em:<http://www.ambito-juridico.com.br/site/index.php?n_link=revista_artigos_ leitura\&artigo_id=6472>. Acesso em set 2016.

WATANABE, Kazuo, (coords.) Acesso à Justiça e a Sociedade Moderna. In: GRINOVER, Ada Pellegrini; DINAMARCO, Cândido Rangel; WATANABE, Kazuo, (coords.). Participação e Processo. São Paulo: Revista dos Tribunais, 1988. 